\title{
Comparison of the Post-Operative Response of Tumour Necrosis Factor- $\alpha$ and Interleukin-6 in Inguinal Hernioplasty
}

\author{
Rohith Holla ${ }^{1}$, Nawin Kumar ${ }^{2}$ \\ ${ }^{1}$ Department of General Surgery, Justice K. S. Hegde Charitable Hospital, Mangaluru, Karnataka, India. \\ ${ }^{2}$ Department of General Surgery, Justice K. S. Hegde Charitable Hospital, Mangaluru, Karnataka, India.
}

ABSTRACT

\section{BACKGROUND}

Inguinal hernia is the commonest groin swelling. Some of the common predisposing factors to inguinal hernia are COPD, BPH and chronic constipation. This study aims to determine the post-operative significance of Interleukin-6 (IL-6) and Tumour Necrosis Factor- $\alpha$ (TNF- $\alpha$ ) following open- and laparoscopic- TEP repair inguinal hernioplasty in the detection of tissue trauma.

\section{METHODS}

This study was conducted in the department of General Surgery from January 2017 June 2018 in Justice K. S. Hegde Charitable Hospital. The post-operative response of IL- 6 and TNF- $\alpha$ was assessed among 40 patients undergoing open and laparoscopicTEP repair inguinal hernioplasty. Mann-Whitney $U$ test was used and the $p$-Value of $<0.05$ is considered statistically significant.

\section{RESULTS}

The post-operative rise in TNF- $\alpha$ following laparoscopic hernioplasty was statistically significant when compared to the open procedure (unilateral hernioplasty: p-Value- 0.04 and bilateral hernioplasty: p-Value- 0.009). No significant change was noted in IL-6 (unilateral hernioplasty: p-Value- 0.65 and Bilateral hernioplasty: p-Value- 0.29)

\section{CONCLUSIONS}

The post-operative change in TNF- $\alpha$ was considered significant when compared to IL-6. Thus, showing that TNF- $\alpha$ is a more reliable indicator of tissue trauma.

\section{KEY WORDS}

Tumour Necrosis Factor- $\alpha$, Interleukin- 6 Inguinal Hernioplasty
Corresponding Author:

Nawin Kumar,

Department of General Surgery,

Justice K. S. Hegde Charitable Hospital,

Deralakatte, Mangluru-575018,

Karnataka, India.

E-mail: neonawin@gmail.com

DOI: $10.14260 /$ jemds/2019/758

Financial or Other Competing Interests: None.

How to Cite This Article:

Holla R, Kumar N. Comparison of the postoperative response of tumour necrosis factor- $\alpha$ and interleukin- 6 in inguinal hernioplasty. J. Evolution Med. Dent. Sci. 2019;8(47):3505-3507,

$10.14260 /$ jemds $/ 2019 / 758$

Submission 21-09-2019,

Peer Review 08-11-2019,

Acceptance 13-11-2019,

Published 25-11-2019. 


\section{BACKGROUND}

A hernia is defined as the disruption/weakness in the fibromusculature of the body wall leading to abnormal protrusion of the viscus/ part of the viscus through an opening with a sac enclosing it. Inguinal hernia constitutes $73 \%$ of all the groin swellings. ${ }^{1}$ Indirect hernia is common among men and women. ${ }^{2}$ The common laparoscopic repairs performed are TEP and TAPP repair. The different types of open repair are Lichtenstein Tension Free hernioplasty, Modified Rives- Stoppa pre-peritoneal mesh repair; NYHUS pre-peritoneal mesh repair, Stoppa's GPRVS repair. In our study, we have performed Lichtenstein Tension Free hernioplasty and laparoscopic TEP repair (Unilateral as well as Bilateral). The parameters used in our study are serum TNF- $\alpha$ \& IL-6, obtained 6 hours after either of the procedure. Tumour Necrosis Factor- $\alpha$ is a pro-inflammatory cytokine from the Golgi complex of Macrophages, T- lymphocytes and dendritic cells. ${ }^{3}$ Interleukin- 6 is a pro-inflammatory cytokine with a half-life of 6 hours. A potent inducer of CRP and Fibrinogen from the Hepatocytes. It modulates the lymphocytic response of antibody production and cellmediated immunity. 4

\section{METHODS}

Our study is a Prospective study (Institutional Ethics Committee approval obtained in October 2016) conducted in the period of January 2017- June 2018 in the department of General Surgery, Justice K.S. Hegde Charitable Hospital. Patients undergoing open or laparoscopic (Unilateral and Bilateral) inguinal hernioplasty on an elective basis. Total of 40 subjects were involved in the study [Sample size of 40 patients was obtained by using the formula; $\mathrm{N}=\mathrm{Z} 2 \mathrm{P} \times(100$ P)/ D2 N - Sample size; Z - Appropriate value for normal distribution ( $\mathrm{Z}=1.96) ; \mathrm{P}$ - Anticipated prevalence (In this study, P = 14\%);D - Desired precision (In this study, D= 10 )], the study population was further divided into 10 open $\mathrm{U} / \mathrm{L}$ inguinal hernioplasty, 10 open $\mathrm{B} / \mathrm{L}$ inguinal hernioplasty, 10 laparoscopic U/L inguinal hernioplasty, 10 laparoscopic B/L inguinal hernioplasty.

After 6 hours of either procedure, the blood was drawn from the patient after obtaining due consent from the patient. TNF- $\alpha$ and IL- 6 was analysed using DIACLONE ${ }^{\text {TM }}$ Human ELISA kits. $2 \mathrm{ml}$ of blood was drawn from the patient pre-op and 6 hours after surgery for assessment of TC, DC in EDTA vacutainer and $3 \mathrm{ml}$ of blood in plain vacutainer is collected for the estimation of TNF $-\alpha$, IL-6. The plain sample once clotted, is subjected to centrifugation at $4500-5000 \mathrm{rpm}$ for $5 \mathrm{~min}$ for serum extraction $0.5 \mathrm{ml}$ each of serum was used to estimate TNF- $\alpha$ and IL- 6 by means of ELISA method at Central Research laboratory of K.S Hegde Medical Academy.

The study excluded patients with auto-immune disease such as SLE; RA. Obstructed/Strangulated hernia. Patients undergoing TAPP (Trans Abdominal Pre-Peritoneal) repair.

\section{Statistical Analysis}

The statistical analysis was done using Microsoft Excel 2010 version 14 Software and SPSS 22.0 (SPSS Inc. Chicago. II, USA). The pre-operative value was compared with post- operative values using Wilcoxon singed rank test and the $\mathrm{p}$ Value of $</=0.05$ was considered significant.

\section{RESULTS}

\begin{tabular}{|c|c|c|c|}
\hline $\begin{array}{c}\text { Inguinal } \\
\text { Hernioplasty }\end{array}$ & $\begin{array}{l}\text { Median Pre-op } \\
\text { TNF- } \alpha(\mathrm{pg} / \mathrm{ml})\end{array}$ & $\begin{array}{c}\text { Inter Quartile } \\
\text { Range }\end{array}$ & $\begin{array}{l}\text { p }(</=0.05, \\
\text { Significant) }\end{array}$ \\
\hline Open U/L & 25.4 & $6.3-50$ & 0.74 \\
\hline Laparoscopic U/L & 36.9 & $28.7-47$ & (Not significant) \\
\hline Open B/L & 20.4 & $14.7-25.03$ & 0.68 \\
\hline Laparoscopic B/L & 38.7 & $30.2-50.8$ & (Not significant) \\
\hline
\end{tabular}

\begin{tabular}{|c|c|c|c|}
\hline $\begin{array}{c}\text { Inguinal } \\
\text { Hernioplasty }\end{array}$ & $\begin{array}{c}\text { Median Post-op } \\
\text { TNF- } \alpha \text { (pg/ml) }\end{array}$ & $\begin{array}{c}\text { Inter-Quartile } \\
\text { Range }\end{array}$ & $\begin{array}{l}\text { p }</=0.05, \\
\text { Significant }\end{array}$ \\
\hline Open U/L & 43.7 & $(22.4-81)$ & \multirow{2}{*}{$\begin{array}{c}0.04 \\
\text { (Significant) }\end{array}$} \\
\hline Laparoscopic U/L & 62.5 & (40.5-81.1) & \\
\hline Open B/L & 37.33 & $(30.5-48.4)$ & \multirow{2}{*}{$\begin{array}{c}0.009 \\
\text { (Significant) }\end{array}$} \\
\hline Laparoscopic B/L & 66.4 & $(49.9-68.13)$ & \\
\hline
\end{tabular}

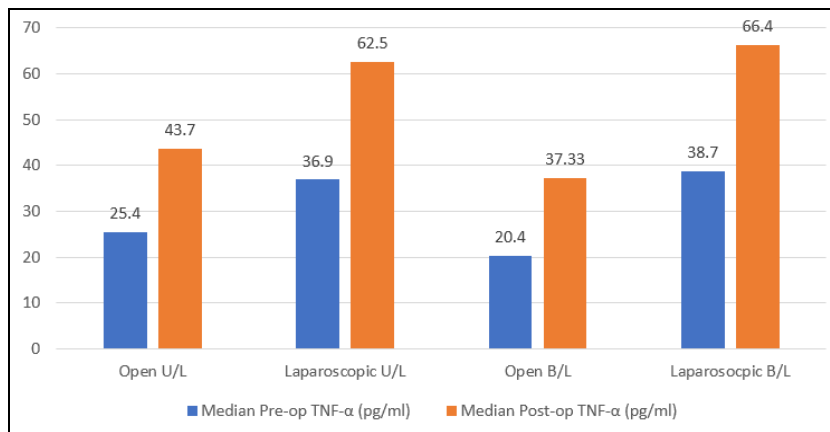

Figure 1. Comparison of Pre-Operative and Post-Operative TNF- $\alpha$ : Open vs Laparoscopic Inguinal Hernioplasty

\begin{tabular}{|c|c|c|c|}
\hline $\begin{array}{c}\text { Inguinal } \\
\text { Hernioplasty }\end{array}$ & $\begin{array}{c}\text { Median } \\
\text { Pre-op IL-6 }\end{array}$ & $\begin{array}{c}\text { Inter Quartile } \\
\text { Range }\end{array}$ & $\begin{array}{c}\text { p (</= 0.05, } \\
\text { Significant) }\end{array}$ \\
\hline Open U/L & 44.8 & $28-62.4$ & 0.59 \\
Laparoscopic U/L & 47.7 & $33.2-62.4$ & (Not significant) \\
\hline Open B/L & 46.5 & $37.6-56.1$ & 0.60 \\
Laparoscopic B/L & 57.7 & $40-61.9$ & (Not significant) \\
\cline { 1 - 2 } Table 3. Comparison of Pre-Operative IL-6 (Baseline): \\
Open vs Laparoscopic Inguinal Hernioplasty \\
\hline
\end{tabular}

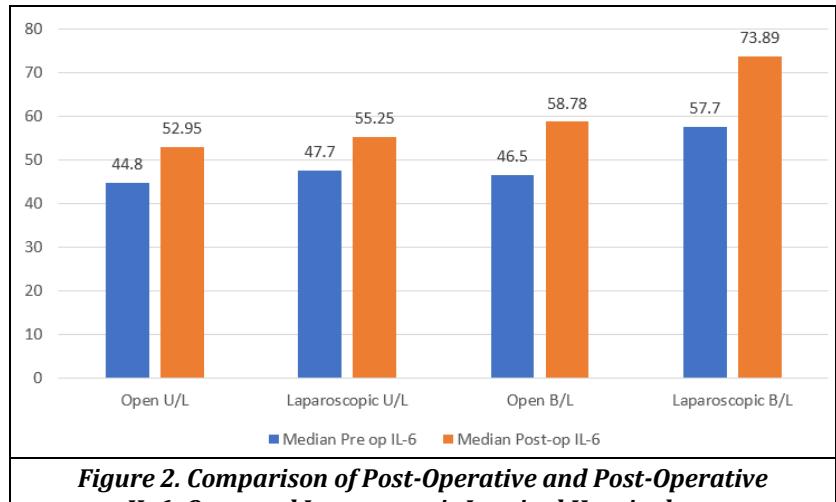

IL-6: Open and Laparoscopic Inguinal Hernioplasty

Hernioplasty

\begin{tabular}{|c|c|c|c|}
\hline $\begin{array}{c}\text { Inguinal } \\
\text { Hernioplasty }\end{array}$ & $\begin{array}{c}\text { Median } \\
\text { Post-op IL-6 }\end{array}$ & $\begin{array}{c}\text { Inter-Quartile } \\
\text { Range }\end{array}$ & $\begin{array}{l}\mathrm{p}</=0.05, \\
\text { Significant }\end{array}$ \\
\hline Open U/L & 52.95 & $(44.5-62)$ & \multirow{2}{*}{$\begin{array}{c}0.65 \\
\text { (Not significant) }\end{array}$} \\
\hline Laparoscopic U/L & 55.25 & $(44.3-75)$ & \\
\hline Open B/L & 58.78 & $(45.5-70)$ & \multirow{2}{*}{$\begin{array}{c}0.29 \\
\text { (Not significant) }\end{array}$} \\
\hline Laparoscopic B/L & 73.89 & $(48.5-81)$ & \\
\hline
\end{tabular}

Inguinal Hernioplasty 


\section{DISCUSSION}

Our study compares the response of TNF- $\alpha$ and Interleukin- 6 in post-operative status. This study excludes patients with auto-immune diseases and obstructed Inguinal hernia- the condition in which there is rise of acute inflammatory mediators before the intervention ${ }^{4}$ and patients undergoing TAPP repair, as its not frequently performed compared to TEP repair at our institution.

Prospective study conducted by Schrenk. $\mathrm{P}$ et $\mathrm{al}^{5}$ on 'Metabolic responses after laparoscopic and open hernia repair comprised of 15 patients in each group. The parameters compared were TC, IL-6, TNF- $\alpha$, CRP. The p-value of $<0.05$ was considered significant. The changes in TC, DC, CRP, TNF- $\alpha$, IL- 6 were not significant, where as our study shows a significant rise in TNF- $\alpha$ in the group subjected to laparoscopic Inguinal hernioplasty.

In 2002 Suter $\mathrm{M}$ et $\mathrm{al}^{6}$ conducted a prospective study on 'Reduced acute phase response after laparoscopic (TEP repair) compared with open repair'. The study had 39 patients in both groups. The inflammatory mediators assessed were TC, Neutrophils, Lymphocytes, CRP, IL-6 and TNF- $\alpha$. The $p$-Value of $</=0.05$ was considered to be significant. The study, showed a significant decrease in the lymphocyte count $(p-$ Value $=0.04)$ and a significant rise was noted in IL-6 $(\mathrm{p}=0.05)$ following open Inguinal hernioplasty. No significant changes were noted in TC, Neutrophils, CRP and TNF- $\alpha$ respectively.

In our study, the change in TNF- $\alpha$ in laparoscopic Inguinal hernioplasty for unilateral hernia repair $(p$-value $=0.04)$ and bilateral hernia repair ( $p$-Value $=0.009$ ) was considered significant on comparing it with its open counterpart, whereas IL-6 showed no significance between open and laparoscopic Inguinal hernioplasty.

Akhtar K et $\mathrm{al}^{7}$ in 1998 conducted a prospective study on 'Metabolic and inflammatory response after laparoscopic and open hernia repair'. The study had sample of 10 patients in each group. The change in CRP, IL- 6 and TNF- $\alpha$ was compared between open and laparoscopic inguinal hernioplasty groups. Change in IL-6 levels were not significant. A significant rise was noted in CRP (p-Value $<0.006)$ and TNF- $\alpha(p$-Value $<0.005)$ among the groups of open hernioplasty group.
In our study, TNF- $\alpha$ was the only mediator to display a significant rise in laparoscopic Inguinal hernioplasty when compared to open Inguinal hernioplasty-Unilateral ( $p$-value $=0.04)$ as well as bilateral $(p$-Value $=0.009)$ repair. No significance was noted in CRP and IL- 6 were noted among the groups of open and laparoscopic inguinal hernioplasty respectively.

\section{CONCLUSIONS}

The post-operative change in TNF- $\alpha$ was considered significant when compared to IL-6, thus, showing that TNF- $\alpha$ is a more reliable indicator of tissue trauma.

\section{REFERENCES}

[1] Gould J. Laparoscopy versus open inguinal hernia repair. Surg Clin North Am 2008;88(5):1073-81.

[2] Rutkow IM. Epidemiologic, economic and sociologic aspects of hernia surgery in United States in the 1990s. Surg Clin North Am 1998;78(6):941-51.

[3] Baigrie RJ, Lamount PM, Kwiatkowski D, et al. Systemic cytokine response after major surgery. $\mathrm{Br} \mathrm{J}$ Surg 1992;79(8):757-60.

[4] Jawa RS, Anillo S, Baumann H, et al. Interleukin-6 in surgery, trauma and critical care part II: clinical implications. J Intensive Care Med 2011;26(2):73-87.

[5] Schrenk P, Bettelheim P, Woisetschlager R, et al. Metabolic responses after laparoscopic/open hernia repair. Surg Endosc 1996;10(6):628-32.

[6] Suter M, Martinett 0, Spertini F. Reduced acute phase response after laparoscopic TEP hernia repair compared to open repair with Stoppa procedure. Surg Endosc 2002;16(8):1214-9.

[7] Akhtar K, Kamalky-Asl ID, Lamb WR, et al. Metabolic and inflammatory responses after laparoscopic and open inguinal hernia repair. Ann $\mathrm{R}$ Coll Surg Eng 1998;80(2):125-30. 